\title{
ESTABELECIMENTO E MULTIPLICAÇÃO IN VITRO DE Pyrus calleryana D-6 EM SISTEMA DE CULTURA 'DUPLA-FASE'
}

\author{
LIZIANE KADINE ANTUNES DE MORAES², CLAUDIA FELISBINO³, LEANDRO CRESTANI ${ }^{4}$, \\ APARECIDO LIMA DA SILVA 5
}

\begin{abstract}
RESUMO - Este trabalho objetivou estabelecer e propagar in vitro o porta-enxerto de pereira Pyrus calleryana D-6. Os explantes foram retirados de plantas-matrizes e submetidos à desinfestação com imersão em álcool a 70\% por dois minutos, seguido de solução de hipoclorito de sódio a 1,5\% + Tween 20 por 20 minutos, e após inoculados em meio MS com BAP $(4,4 \mu \mathrm{M}), \mathrm{AG}_{3}(0,3 \mu \mathrm{M})$ e ANA $(0,05 \mu \mathrm{M})$. Na fase de multiplicação, as microestacas caulinares, contendo 2-3 gemas, foram transferidas para frascos com $50 \mathrm{~mL}$ de meios MS e MS1 modificado com $\left(\mathrm{NH}_{4} \mathrm{NO}_{3}\right) / 2$ e $\left(\mathrm{CaCl}_{2} .2 \mathrm{H}_{2} \mathrm{O}\right) * 2$, suplementados com sacarose $\left(30 \mathrm{gL}^{-1}\right)$, ágar $\left(7 \mathrm{gL}^{-1}\right)$ e diferentes concentrações de $\mathrm{BAP}(0$ e $6,7 \mu \mathrm{M}), \mathrm{AIB}(0$ e $0,5 \mu \mathrm{M}), \mathrm{AG}_{3}(0$ e $0,3 \mu \mathrm{M})$. Para o sistema 'dupla-fase' (líquido-geleificado), os tratamentos receberam, aos 30 dias de cultura in vitro, $10 \mathrm{~mL}$ de meio MS líquido, sem fitorreguladores, e foram avaliados após 60 dias de cultura. Os resultados mostraram que 23,5\% das gemas introduzidas obtiveram proliferação, sendo que o maior problema no estabelecimento in vitro foi a oxidação que afetou $44,8 \%$ das gemas introduzidas. O sistema 'dupla-fase' demonstrou ser muito efetivo para multiplicação in vitro do porta-enxerto de pereira Pyrus calleryana D-6. A maior taxa de multiplicação (16,8 brotos/explante) e o maior comprimento dos brotos ( 33 $\mathrm{mm})$ foram obtidos no meio MS contendo BAP $(6,7 \mu \mathrm{M})$ e AIB $(0,5 \mu \mathrm{M})$.
\end{abstract}

Termos para indexação: Pereira, porta-enxerto, meio de cultura, micropopagação

\section{IN VITRO ESTABLISHMENT AND MULTIPLICATION OF Pyrus calleryana D-6 ON DOUBLE-PHASE CULTURE SYSTEM}

\begin{abstract}
The present work aimed to establish a protocol for the micropropagation of pear rootstock Pyrus calleryana D-6. Explants were excised from mother plants, disinfected with alcohol $70 \%$ (2 minutes), sodium hypocloride $1.5 \%$ and Tween $20\left(10\right.$ drops $\left.\mathrm{L}^{-1}\right)$ during 20 minutes. The explants were transferred to MS medium supplemented with BAP $(4.4 \mu \mathrm{M}), \mathrm{GA}_{3}(0.3 \mu \mathrm{M})$ and NAA $(0.05 \mu \mathrm{M})$. For the multiplication phase the microcuttings (2-3 buds) were transferred to flasks containing $50 \mathrm{~mL}$ of MS and MS1 [culture media modified $\left(\mathrm{NH}_{4} \mathrm{NO}_{3}\right) / 2$ and $2 \times\left(\mathrm{CaCl} 2.2 \mathrm{H}_{2} \mathrm{O}\right)$ ] media. These media were supplemented with sucrose $\left(30 \mathrm{gL}^{-1}\right)$, ágar $\left(7 \mathrm{gL}^{-1}\right)$ and BAP $(0$ and $6.7 \mu \mathrm{M})$, IBA $(0$ and $0.5 \mu \mathrm{M})$ and GA $(0$ and $0.3 \mu \mathrm{M})$. In the 'double-phase' system (liquid gelling) $10 \mathrm{~mL}$ growth regulators free of MS liquid medium were added to the flasks, after 30 days, and the treatments were evaluated 60 days of in vitro culture. The results showed that $23.5 \%$ of the explants presented proliferation. The main constraint for the in vitro establishment was the oxidation that impaired $44.8 \%$ of the explants. The 'double-phase' culture system demonstrated to be effective for in vitro multiplication. The largest multiplication factor (16.8 shoots/explant) and the largest length of the shoots ( $33 \mathrm{~mm})$ were obtained in MS medium containing BAP $(6.7 \mu \mathrm{M})$ and $\operatorname{IBA}(0.5 \mu \mathrm{M})$.
\end{abstract}

Index terms: Pear plant, rootstock, culture medium, micropropagation.

\section{INTRODUÇÃO}

No Brasil, a importação de frutas frescas apresentou valores superiores a US\$112 milhões em 2001, contribuindo de forma expressiva para a evasão de divisas. Dentre as frutas de clima temperado, a pêra se destaca como a terceira fruta de maior consumo e a primeira em volume de importação (Faoro, 2001a; Oliveira Junior \& Manica, 2002).

No País, apesar de a pereira ser cultivada há muitos anos, sua produção em escala comercial ainda é incipiente, sendo de aproximadamente $6.000 \mathrm{t}$, enquanto o consumo é da ordem de $200.000 \mathrm{t}$ (Gayet, 1998; Faoro, 2001a). Verifica-se que um dos fatores que afetam a ampliação e a consolidação da cultura na região Sul consiste na indefinição de porta-enxertos adaptados. Neste contexto, Nakasu \& Leite (1992) e Faoro (2001b) recomendam o porta-enxerto Pyrus calleryana D-6, tanto para cultivares européias como asiáticas, em virtude de sua boa compatibilidade, eficácia produtiva e indução de frutos de excelente qualidade.

Para algumas espécies frutíferas, a propagação in vitro tem sido recomendada e utilizada com sucesso técnico e econômico, principalmente pela rapidez, eficiência de produção e qualidade genéticasanitária do material multiplicado (Damiano \& Palombi, 2000).

Para a pereira, diversos autores têm procurado desenvolver metodologias de propagação in vitro visando à produção clonal de porta-enxertos (Yeo \& Reed, 1995; Shibli et al., 1997). Entretanto, verificase que o gênero Pyrus tem apresentado baixa eficiência na micropropagação, principalmente na fase de multiplicação, onde tem ocorrido baixo número de brotos e/ou qualidade inadequada para o enraizamento (Kadota et al., 2001).

Para Rodríguez et al. (1991) e Kadota et al. (2001), o sistema 'dupla-fase' de cultura in vitro pode ser utilizado com sucesso na micropropagação do gênero Pyrus, principalmente com a finalidade de aumentar a taxa de multiplicação, crescimento dos brotos e redução da hiperidricidade.

Assim, este trabalho teve como objetivo estabelecer e multiplicar in vitro Pyrus calleryana D-6, no sistema 'dupla-fase', visando à propagação clonal deste porta-enxerto de pereira.

\section{MATERIALEMÉTODOS}

O porta-enxerto de pereira (Pyrus calleryana D-6) foi estabelecido in vitro a partir de segmentos caulinares contendo gemas axilares (Figura 2.1) retirados de plantas-matrizes mantidas em casa de vegetação no Departamento de Fitotecnia, CCA, UFSC.

Os explantes foram submetidos à desinfestação com uma lavagem em água + Tween $20\left(10\right.$ gotas $\left.\mathrm{L}^{-1}\right)$, seguido de três rinsagens em água bidestilada, imersão em álcool a 70\% (2 minutos) e 1,5\% de hipoclorito de sódio + Tween 20 (20 minutos). Após, foram transferidos para câmara de fluxo laminar e submetidos a três lavagens com água destilada estéril.

Os explantes, segmentos caulinares contendo 2-3 gemas axilares, foram introduzidos em tubos de ensaio de 20x200 mm contendo $15 \mathrm{~mL}$ de meio de cultura MS (Murashige \& Skoog, 1962), suplementado

\footnotetext{
${ }^{1}$ (Trabalho 182/2002) Recebido: 10/11/2002. Aceito para publicação: 05/11/2004

${ }^{2}$ Acadêmica em Agronomia da Universidade Federal de Santa Catarina, C.P. 476, 88040-900, Florianópolis-SC, (48) 331-5330, bolsista RHAE/CNPq

${ }^{3}$ Acadêmica em Biologia da Universidade do Oeste de Santa Catarina, C.P. 187, 89560-000, Videira-SC, (49) 551-1422, bolsista RHAE/CNPq

${ }^{4}$ Eng $^{\circ}$. Agro ${ }^{\circ}$ Empresa Vitroplanta - Biotecnologia Ltda, C.P. 150, 89.560-000, Videira-SC, (49) 566-2690, bolsista RHAE/CNPq

${ }^{5}$ Prof. Adjunto da Universidade Federal de Santa Catarina, Departamento de Fitotecnia, C.P. 476, 88040-900, Florianópolis-SC, (48) 331-5330, alsilva@ cca.ufsc.br
} 
com 4,4 $\mu \mathrm{M}$ de BAP (6-benzilaminopurina), 0,3 $\mu \mathrm{M}$ de $\mathrm{AG}_{3}$ (ácido giberélico), $0,05 \mu \mathrm{M}$ de ANA (ácido naftalenoacético), $30 \mathrm{gL}^{-1}$ de sacarose e $7 \mathrm{gL}^{-1}$ de ágar. $\mathrm{O} \mathrm{pH}$ do meio de cultura foi ajustado para 5,9 antes da autoclavagem.

Os explantes introduzidos foram mantidos no escuro por 48 horas, sendo, em seguida, transferidos para sala de crescimento com fotoperíodo de 16 horas, temperatura de $25 \pm 1^{\circ} \mathrm{C}$, intensidade luminosa de 40 a $45 \mu \mathrm{mol} \mathrm{m} \mathrm{m}^{-2} \mathrm{~s}^{-1}$ e umidade relativa do ar $60-70 \%$.

Os explantes foram avaliados quanto à percentagem de sobrevivência, oxidação e contaminação por agentes fúngicos e bacterianos, após 15 dias de cultura in vitro.

Para multiplicação in vitro, microestacas caulinares com 2-3 gemas, provenientes da terceira subcultura, foram transferidas para frascos com $50 \mathrm{~mL}$ de meio de cultura MS e MS modificado (MS1) com alteração nas concentrações salinas de $\left(\mathrm{NH}_{4} \mathrm{NO}_{3}\right) / 2$ e $\left(\mathrm{CaCl}_{2} \cdot 2 \mathrm{H}_{2} \mathrm{O}\right) * 2$, conforme recomendação de Rodriguez et al. (1991). Foram avaliadas também diferentes concentrações de BAP $(0$ e $6,7 \mu \mathrm{M})$, AIB $(0$ e $0,5 \mu \mathrm{M})$, $\mathrm{AG}_{3}(0 \mathrm{e} 0,3 \mu \mathrm{M})$. Os meios de cultura foram suplementados com sacarose (30 $\left.\mathrm{gL}^{-1}\right)$, ágar $\left(7 \mathrm{gL}^{-1}\right)$ e $\mathrm{pH}$ ajustado para 5,9.

Para a avaliação do sistema 'dupla-fase' (líquido-geleificado), 30 dias após em cultura in vitro, os mesmos tratamentos receberam a adição de $10 \mathrm{~mL}$ de MS líquido sem fitorreguladores. Após 60 dias em cultura, os parâmetros avaliados foram número e comprimento das brotações por explante.

$\mathrm{Na}$ fase de estabelecimento in vitro, os dados foram avaliados quanto à percentagem de sobrevivência, oxidação e contaminação. Para a fase de multiplicação, o delineamento experimental adotado foi o inteiramente ao acaso, com cada unidade experimental constituída por cinco microestacas e repetidas cinco vezes. Os dados de número e comprimento médio das brotações $(\mathrm{mm})$ foram submetidos à análise de variância (ANOVA) e ao teste de separação de médias SNK (5\%), de acordo com Sokal \& Rohlf (1995)

\section{RESULTADOS E DISCUSSÃO}

Os resultados para o estabelecimento in vitro são apresentados na Figura 1. Verificou-se que somente 23,5\% das gemas estabelecidas demonstraram capacidade de proliferação (Figura 2.2). Esta percentagem de sobrevivência de explantes é considerada baixa para a fase de introdução in vitro. Silva et al. (1997) obtiveram 65\% de explantes sobreviventes para diferentes porta-enxertos de videira. Para pessegueiro, Rogalski (2002) obteve taxas de 63\% e 59\% de sobrevivência para explantes oriundos de ápic es caulinares e gemas laterais, respectivamente. Yeo \& Reed (1995) obtiveram alta percentagem de sobrevivência (>90\%), a partir de gemas dormentes para três portaenxertos de pereira; no entanto, gemas provenientes de ramos em crescimento vegetativo o estabelecimento in vitro foi dificultado por problemas de oxidação e contaminação.

No processo de estabelecimento in vitro, houve contaminação fúngica e bacteriana em $25,1 \%$ e $6,6 \%$ dos explantes introduzidos, respectivamente (Figura 1). As contaminações por bactérias em espécies lenhosas são geralmente de origem endógena. Neste sentido, os processos de desinfestações comumente utilizados são pouco eficientes.

O fator de maior limitação para introdução in vitro de Pyrus calleryanna D-6 foi a alta taxa de oxidação dos explantes $(44,8 \%)$. Este processo foi mais acentuado na fase de estabelecimento in vitro dos explantes e no primeiro subcultivo. Observações semelhantes foram feitas em Pyrus calleryana 'OPR 157' e Pyrus betulifolia 'OPR 260' (Yeo \& Reed, 1995), em Pyrus syrica (Shibli et al., 1997) e em Musa spp. (Oliveira et al., 2001)

O uso da metodologia de 'dupla-fase' (líquido-geleificado) aumentou significativamente o número de brotos e o comprimento das brotações de Pyrus calleryana D-6 (Tabela 1, Figura 2.3). Segundo Rodriguez et al., (1991), este método aumenta a quantidade e a qualidade das brotações in vitro de pereira. Para estes autores, é um sistema versátil que permite manter a cultura constantemente em proliferação por maior período de tempo, com adição de uma quantidade de meio líquido apropriado.

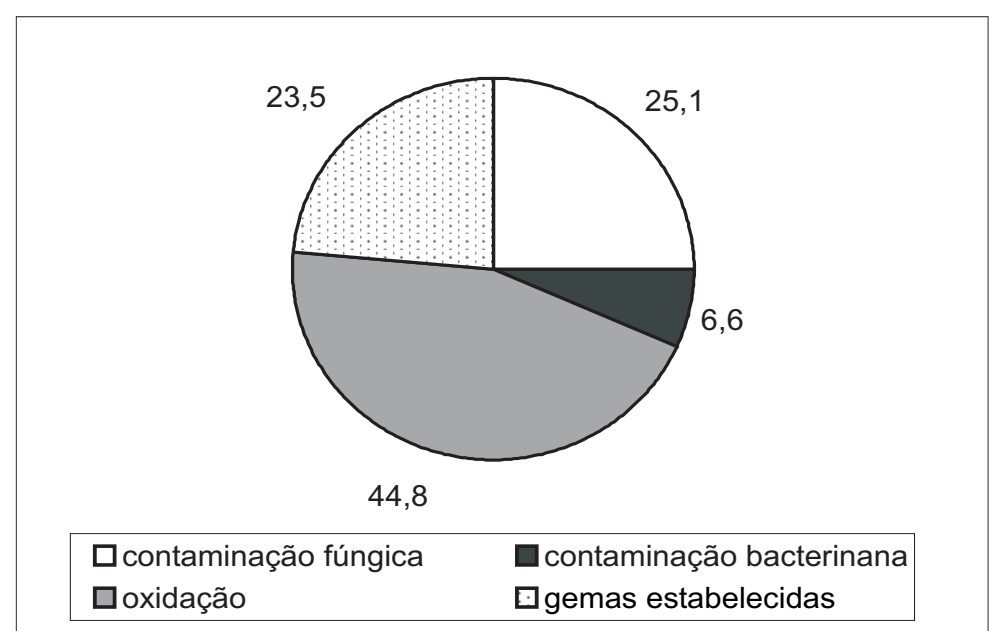

FIGURA 1 - Percentagens de gemas estabelecidas, oxidação e contaminações (fúngica e bacteriana) no estabelecimento in vitro do porta-enxerto de pereira Pyrus calleryana D6. UFSC, Florianópolis-SC, 2001

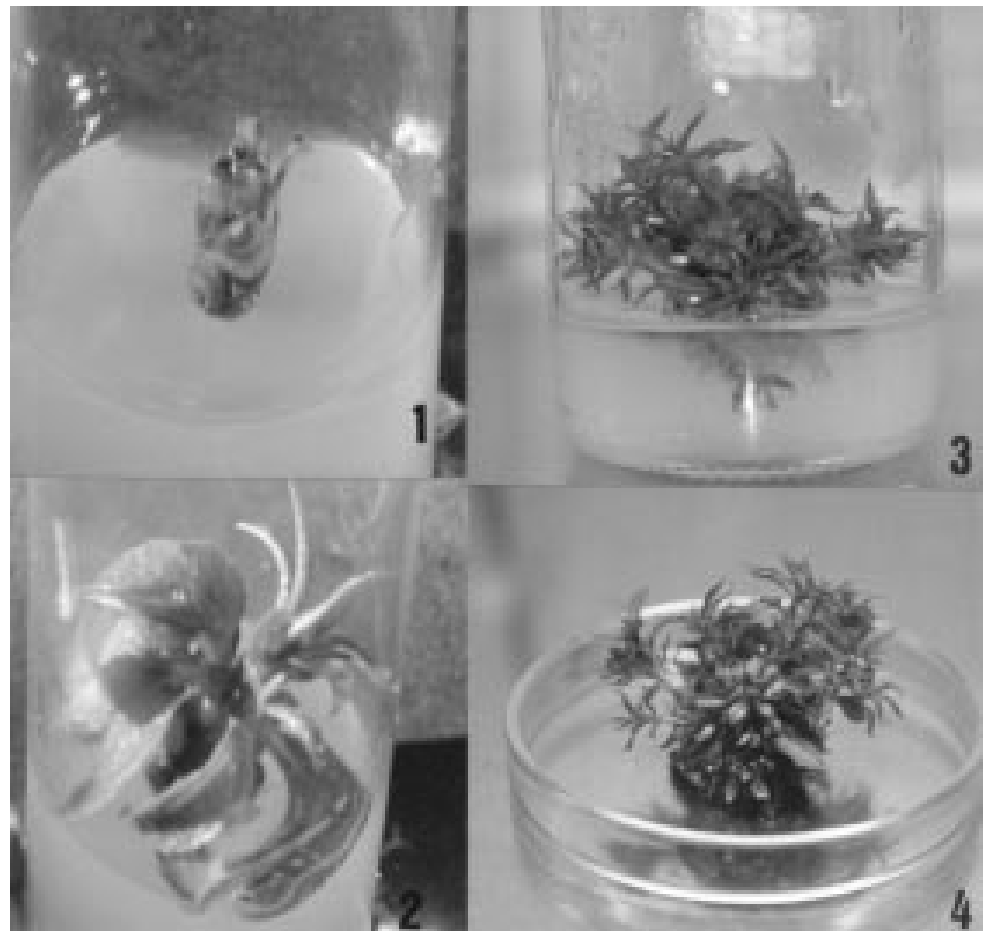

FIGURA 2 - Aspectos morfológicos do porta-enxerto de pereira Pyrus calleryana D-6 in vitro. 1) Segmento caulinar introduzido in vitro. 2) Explante em crescimento in vitro. 3 e 4) Brotações múltiplas de gemas axilares em sistema 'duplafase', após 60 dias em cultura in vitro. UFSC, FlorianópolisSC, 2001

A combinação de BAP $(6,7 \mu \mathrm{M})$ e AIB $(0,5 \mu \mathrm{M})$, suplementada ao meio de cultura básico MS, promoveu maior ( 16,8 brotos) e significativo $(\mathrm{P}<0,05)$ número de brotos por explante (Tabela 1). A combinação de BAP e AIB apresentou resultados superiores tanto para os meios de cultura com sais de MS como de MS1. Desta forma, verificou-se que em Pyrus calleryana D-6 o uso de meio de cultura com redução de $\mathrm{N}$ e acréscimo de Ca mostrou-se inferior ao MS original. Estes resultados foram superiores aos observados por Rodriguez et al. (1991) e Kadota et al. (2001) para pereira européia (Pyrus communis L.) e pereira japonesa (Pyrus pyrifolia N.), respectivamente. Os tratamentos acrescidos somente de BAP foram inferiores à combinação de BAP e AIB, apresentando taxas de 6 e 7 brotos/explante. Já, os tratamentos isentos de fitorreguladores e a combinação de $\mathrm{BAP}, \mathrm{AIB}$ e $\mathrm{AG}_{3}$ não diferiram entre 
TABELA 1 - Efeito do meio de cultura e de reguladores de crescimento na multiplicação do porta-enxerto de pereira Pyrus calleryana D-6 em sistema 'dupla-fase', após 60 dias em cultura in vitro. UFSC, Florianópolis-SC, 2001.

\begin{tabular}{|c|c|c|c|c|c|}
\hline \multicolumn{4}{|c|}{ Tratamentos } & \multicolumn{2}{|c|}{ Resultados } \\
\hline Meio & BAP( $\mathbf{M})$ & $\operatorname{AIB}(\mathbf{M})$ & $\mathrm{AG}_{3}(\mathrm{M})$ & $\mathbf{N}^{0}$ brotações & Comprimento $(\mathrm{mm})$ \\
\hline \multirow[t]{3}{*}{$\mathrm{MS}$} & 0,0 & 0,0 & 0,0 & $1,1 \quad \mathrm{~d}$ & 8,8 \\
\hline & 6,7 & 0,0 & 0,0 & $6,0 \quad \mathrm{c}$ & $13,0 \quad \mathrm{Bc}$ \\
\hline & 6,7 & 0,5 & 0,3 & $2,0 \quad \mathrm{~d}$ & $8,0 \quad \mathrm{C}$ \\
\hline \multirow[t]{2}{*}{$\overline{M S 1}$} & 0,0 & 0,0 & 0,0 & 1,3 & 7,5 \\
\hline & 6,7 & 0,0 & 0,0 & 7,0 & 16,0 \\
\hline
\end{tabular}

Médias seguidas de mesma letra não diferem significativamente entre si, ao nível de 5\% de probabilidade (SNK).

si, no entanto foram inferiores estatisticamente aos demais tratamentos. A ausência de BAP, $\mathrm{AIB}$ e $\mathrm{AG}_{3}$ não apresenta proliferação de gemas axilares, indicando, portanto, a necessidade destes reguladores para a multiplicação in vitro de Pyrus calleryana D-6.

A presença de $\mathrm{AG}_{3}$ no meio de cultura apresentou um efeito inibitório na proliferação de gemas axilares de Pyrus calleryana D-6. Combinações de $\mathrm{AG}_{3}$ e AIB também inibiram o efeito indutivo do BAP, reduzindo a proliferação e a formação de gemas adventícias, além de serem ineficazes para o alongamento de brotos para diferentes cultivares de pereira (Rodriguez et al., 1991 e Mello-Farias et al., 1995).

É importante salientar que os resultados obtidos no sistema dupla-fase (16,8 brotos/explante) são superiores aos observados, em meios com ágar, no laboratório de Morfogênese e Bioquímica Vegetal (UFSC) para a multiplicação de $P$. calleryana D-6. Para os meios geleificados, a taxa média de multiplicação é de 4,8 brotos/explante (dados não publicados). Estes resultados, em sistema dupla-fase, também são superiores aos relatados por Yeo \& Reed (1995) e Mello-Farias et al. (1995) para Pyrus calleryana Dec.

Com relação ao comprimento das brotações (Tabela 1), verificouse que os tratamentos com meio MS e MS modificado (MS1) contendo $\mathrm{BAP}(6,7 \mu \mathrm{M})+\mathrm{AIB}(0,5 \mu \mathrm{M})$ foram superiores estatisticamente aos demais, apresentando valores médios de 33 e $31 \mathrm{~mm}$, respectivamente. Os tratamentos contendo $\mathrm{BAP}$ ou $\mathrm{BAP}+\mathrm{AIB}+\mathrm{AG}_{3}$ não deferiram entre si, no entanto foram superiores estatisticamente aos tratamentos isentos de fitorreguladores. Os resultados demonstraram que ocorreu um acréscimo acentuado no comprimento das brotações, principalmente para os meios contendo BAP e AIB, que estimularam positivamente o alongamento das brotações in vitro de Pyrus calleryana D-6 (Figura 2.3). Estes resultados são similares aos observados por Rodriguez et al. (1991) para três cultivares de pereira, salientando um aumento significativo do número de brotos de comprimento superior a $3 \mathrm{~cm}$. Neste sentido, Kadota et al. (2001) observaram que o uso do sistema 'dupla-fase' permite o incremento da fitomassa in vitro em pereira japonesa (Pyrus pyrifolia $\mathrm{N}$.).

$\mathrm{O}$ acréscimo na quantidade e qualidade das brotações na multiplicação in vitro, com comprimento superior a $30 \mathrm{~mm}$ (Figura 2.4), é fundamental para a fase de enraizamento in vitro ou para o enraizamento das microestacas diretamente no substrato (Yeo \& Reed, 1995). Desta forma, atenua o grave problema imposto pelo meio geleificado na multiplicação in vitro de Pyrus com o excesso de brotações de comprimento reduzido, inferior a $10 \mathrm{~mm}$ (Shibli et al., 1997).

\section{CONCLUSÕES}

O sistema de multiplicação in vitro 'dupla-fase' (líquidogeleificado) incrementa a taxa de proliferação de gemas axilares, permitindo o aumento da quantidade e qualidade das brotações in vitro. A taxa de multiplicação (16,8 brotos/explante) e o comprimento das brotações $(33 \mathrm{~mm})$ são satisfatórios para o estabelecimento de um protocolo de propagação in vitro deste porta-enxerto de pereira.

\section{REFERÊNCIAS}

DAMIANO, C.; PALOMBI, M.A. La micropropagazione 20 anni dopo: innovazioni tecniche e ottimizzazione dei protocolli delle colture in vitro. Rivista di Frutticoltura, Bologna, v.62, n.2, p.48-55, 2000.

FAORO, I.D. Nashi, a pêra japonesa. In: EPAGRI. Nashi, a pêra japonesa. Florianópolis: Epagri/Jica, 2001a. p.15-65.

FAORO, I.D. Cultivares e porta-enxertos. In: EPAGRI. Nashi, a pêra japonesa. Florianópolis: Epagri/Jica, 2001b. p.95-138.

GAYET, J.P. Tendência e perspectivas do mercado de frutas de clima temperado. In: SEMINÁRIO NACIONAL DA MAÇÃ E DA PÊRA, 1998, São Joaquim.

KADOTA, M.; IMIZU, K.; HIRANO, T. Double-phase in vitro culture using sorbitol increases shoot proliferation and reduces hyperhydricity in Japanese pear. Scientia Horticulturae, Amsterdam, v.89, p. 207-215, 2001.

MELLO-FARIAS, C.P.; PETERS, A.J.; NAKASU, H.B. Micropropagação de porta-enxerto de pereira Pyrus calleryana D-6. Revista Brasileira de Fruticultura, Cruz das Almas, v.17, n.1, p.109-120, 1995.

MURASHIGE, T.; SKOOG, F. A revised medium for rapid growth and bioassay with tobacco tissue cultures. Physiologia Plantarum, Copenhagen, v.15, p.473-497, 1962.

NAKASU, H. B.; LEITE, L. D. Pyrus 9 - Seleção de pereira para o sul do Brasil. Horti Sul, Pelotas, v.2, n.3, p.19-20, 1992.

OLIVEIRA, R.P.; SILVEIRA, D.G.; SILVA, S.O. Concentração de BAPe a eficiência de micropropagação de bananeira tetraplóide (Grupo AAAB). Scientia Agricola, Piracicaba, v.58, n.1, p.73-78, 2001.

OLIVEIRA JUNIOR, M.E.; MANICA, I. Principais países produtores de frutas no ano de 2002. Disponível em: <http://www.ibraf.org.br/xes/pdf/t-esta_iol0403.pdf >. Acesso em: 15 outubro 2004.

RODRÍGUEZ, R.; DÍAZ-SALA, C.; CUOZZO, L.; ANCORA, G. Pear in vitro propagation using a double-phase culture system. HortScience, Alexandria, v.26, n.1, p.62-64, 1991.

ROGALSKI, M. Propagação in vitro de porta-enxertos de Prunus: cultura de embriões, estabelecimento, multiplicação, enraizamento e aclimatização. 2002. 93f. Dissertação (Mestrado em Recursos Genéticos Vegetais). Centro de Ciências Agrárias, Universidade Federal de Santa Catarina, Florianópolis, 2002.

SHIBLI, R.A.; AJLOUNI, M.M.; JARADAT, A.; ALJANABI, S.; SHATNAWI, M. Micropropagation in wild pear (Pyrus syrica). Scientia Horticulturae, Amsterdam, v.68, p.237-242, 1997.

SILVA, A.L. da; SCHUCK, E.; HARISCAIN-LAFITTE, P.; PARIZZOTTO, A. Cultura in vitro do porta-enxerto de videira var. 043-43 resistente a fusariose. In: SIMPÓSIO BRASILEIRO DE MELHORAMENTO DE FRUTÍFERAS, 1., 1997, Jaboticabal. Anais... p. 51-53.

SOKAL, R.R.; ROHLF, F.J. Biometry. 3. ed. San Francisco: Freeman and Company, 1995. 776p.

YEO, Y. D.; REED, M. B. Micropropagação of three Pyrus rootstocks. HortScience, Alexandria, v.30, n.3, p.620-623, 1995. 